\title{
Mewujudkan SDM Unggul di Bidang Perdagangan melalui Corporate University
}

\author{
'Nadya Megawati Rachman, 2Ratnaningsih Hidayati \\ 1,2Pusat Pendidikan dan Pelatihan Perdagangan \\ Article history \\ Received : 4 August 2020 \\ Revised : 11 August 2020 \\ Accepted : 18 August 2020 \\ *Corresponding author \\ Nadya Megawati Rachman \\ Email : nadya.megawati@kemendag.go.id
}

\begin{abstract}
Abstrak
Sebagai alat strategis organisasi di bidang pengembangan kompetensi Sumber Daya Manusia, inisiasi pembentukan Kemendag Corporate University memerlukan suatu cetak biru. Oleh karena itu, tujuan penulisan dari makalah ini adalah membuat desain awal kerangka berpikir (thinking framework) untuk pengembangan Kemendag Corporate University. Metode yang digunakan dalam penelitian ini adalah dengan melakukan kajian pustaka ilmiah yang relevan. Hasil studi menunjukan bahwa Inisiasi Kemendag Corporate University seyogyanya dimulai dengan perubahan paradigma tentang pembelajaran (learning) dari seluruh pemangku kepentingan terkait. Pondasi dari pergeseran paradigma ini adalah adanya strategi dan kepemimpinan pembelajaran yang baik dengan inisiatif perubahan yang dimulai oleh puncak pimpinan organisasi. Terdapat lima pilar Kemendag Corporate University yaitu Integrated Career Path and Human Capital Development, Knowledge Management, Learning Innovation, Network dan Partnership, dan Backbone Infrastructure.
\end{abstract}

Keywords: Corporate University, Thinking Framework, Kementerian Perdagangan

\begin{abstract}
As an organization's strategic tool for developing Human Resources competencies, the initiation of the formation of the Ministry of Trade Corporate University requires a blueprint. Therefore, the purpose of writing this paper is to create an initial thinking framework for the development of the Ministry of Trade's Corporate University. The analytical method used in this research is to study relevant scientific literature. The results of the study show that the Ministry of Trade's Corporate University Initiation should start with a paradigm shift about learning from all relevant stakeholders. The foundation of this paradigm shift is the existence of a good learning strategy and leadership with a change initiative initiated by the top leadership of the organization. There are five pillars of the Ministry of Trade, Corporate University, namely Integrated Career Path and Human Capital Development, Knowledge Management, Learning Innovation, Network and Partnership, and Backbone Infrastructure.
\end{abstract}

Keywords: Corporate University, Thinking Framework, Ministry of Trade

(C) 2020 Pusdiklat Perdagangan. All rights reserved 


\section{PENDAHULUAN}

Bagi pegawai yang bekerja pada sektor pemerintahan, salah satu faktor kunci yang memberikan kepuasan kerja adalah meaningful work (Houston, 2000), yaitu mendapatkan suatu pekerjaan yang memiliki makna lebih dari sekedar untuk memenuhi kebutuhan hidup, makna mendalam yang mengindikasikan terdapat suatu nilai dan manfaat yang dapat didedikasikan, bagi diri sendiri, organisasi maupun bagi masyarakat luas. Terdapat suatu nilai intrinsik yang menjadi reward dari pekerjaan yang menjadi suatu hal penting dan memberikan motivasi yang kuat untuk mencapai visi dan misi organisasi.

Pemerintah mempunyai tantangan untuk dapat mendorong pegawai untuk berinovasi dan menghasilkan suatu kinerja yang mampu memenuhi harapan dari masyarakat. Kesempatan untuk mengembangkan diri dan peluang untuk berkarir merupakan hal penting yang harus dapat diciptakan dalam suatu lingkungan kerja, termasuk dalam organisasi pemerintahan. Untuk mewujudkan hal tersebut, sebagian besar instansi pengembangan sumber daya manusia di dalam dunia pemerintahan telah melirik dan menganut konsep Corporate University.

Konsep Corporate University muncul sejak abad ke 19 di Amerika Serikat, seiring dengan fenomena knowledged worker dan learning organization (Allen, 2002). Konsep ini banyak diadopsi oleh perusahaan swasta dalam penyelenggaraan pelatihan dan pendidikan internal karyawan. Setelah melihat kesuksesan yang dicapai oleh sektor swasta dalam menciptakan suatu pengelolaan sumber daya manusia yang tercermin dari tingkat kepuasan kerja serta tingkat pencapaian karyawan dalam mewujudkan visi serta misi organisasinya, konsep ini mulai diterapkan di organisasi nirlaba juga di instansi pemerintahan. Sebagai alat strategis organisasi di bidang pengembangan kompetensi Sumber Daya Manusia, inisiasi pembentukan Kemendag Corporate University memerlukan cetak biru untuk melakukan inisiasi pengembangan Corporate University ini. Oleh karena itu, penulis menawarkan desain awal kerangka berpikir (thinking framework) untuk pengembangan Kemendag Corporate University.
Terdapat beberapa pustaka yang mendeskripsikan definisi dari Corporate University, menurut Allen (2014) adalah sebuah metode strategis yang bertujuan untuk mencapai tujuan organisasi dengan berfokus pada pelaksanaan kegiatan pengembangan diri pegawai yaitu pembelajaran dan pendidikan. Gonzales (2017) menyatakan bahwa Corporate University menyelaraskan fungsi strategik organisasi dengan integrasi pengelolaan sumber daya manusia yang fokus terhadap kesempatan untuk belajar, pola karir dan sistem penghargaan yang jelas serta manajemen pengetahuan yang tepat.

Terdapat beberapa budaya organisasi yang harus ditanamkan dalam menjalankan Corporate University, diantaranya proaktif terhadap memenuhi kebutuhan organisasi bahkan dapat mempersiapkan kebutuhan dan tantangan organisasi di masa yang akan datang (El-Tannir, 2002). Corporate University juga mensyaratkan agar proses dan dampak yang dihasilkan dari pembelajaran dapat terukur, terdapat rekam jejak yang menyeluruh terhadap perkembangan seorang pegawai pasca pembelajaran (Abel dan Li, 2012).

Corporate University juga memberikan dampak yang luas dan memiliki pengaruh yang dapat dirasakan oleh semua stakeholder dalam suatu organisasi. Terdapat suatu integrasi antara sistem ilmu pengetahuan dengan pembelajar, kerjasama dengan para ahli, metode pembelajaran yang inovatif dan berbagai aspek pendukung lainnya. Corporate University juga disebut sebagai a new generation of strategic learning initiatives (Allen 2007), pengambilan keputusan terlihat jelas pada tingkat organisasi yang lebih tinggi dalam pengelolaan inisiatif ini dibandingkan dengan yang biasa terjadi dalam mengelola pelatihan dan pengembangan dengan tujuan memberikan nilai tambah pada organisasi. Konsistensi dan komitmen tinggi dari pimpinan dibutuhkan untuk menanamkan budaya organisasi dan nilainilai yang ingin diterapkan dalam membangun sebuah Corporate University.

Terdapat pengendalian dari berbagai aktifitas pelatihan dan pengembangan yang 
dilakukan secara lebih efektif dalam rangka mencapai prioritas yang strategis sesuai dengan visi dan misi organisasi, seperti membangun loyalitas pelanggan, kerja lintas budaya, retensi dan pengembangan tingkat tinggi, membuat pelatihan lebih efektif dan efisien atau mengembangkan kepemimpinan. Secara jelas, prioritas strategik organisasi terus berubah menyesuaikan dengan kondisi, kebutuhan dan perkembangan zaman. Aspek Corporate University mencerminkan prioritas strategis yang diberikan untuk pembelajaran. (Paton et al. 2015).

\section{METODOLOGI}

Metode yang digunakan dalam penelitian ini adalah dengan melakukan kajian pustaka ilmiah yang relevan dengan pendekatan deskriptif kualitatif.

\section{HASIL DAN PEMBAHASAN}

Berdasarkan tinjauan literatur dapat disimpulkan bahwa Corporate University merupakan sebuah entitas pengembangan kompetensi sumber daya manusia yang merupakan alat strategis bagi sebuah organisasi untuk mencapai tujuannya, dengan menyelenggarakan kegiatankegiatan yang menanamkan semangat belajar, menambah pengetahuan dan kebijaksanaan baik bagi inividu maupun organisasi secara keseluruhan.

Dokumen Rencana Strategis Kementerian Perdagangan tahun 2020-2024 yang terdapat dalam Peraturan Menteri Perdagangan Nomor 46 tahun 2020 menetapkan visi Kementerian Perdagangan 2020-2024 yaitu "Kementerian Perdagangan yang Andal, Profesional, Inovatif dan Berintegritas untuk Mewujudkan Indonesia Maju yang Berdaulat, Mandiri, dan Berkepribadian Berlandaskan Gotong Royong".

Untuk mewujudkan visi tersebut, salah satu misi Kementerian Perdagangan yang selaras dengan misi Presiden Republik Indonesia adalah "Peningkatan Kualitas Manusia Indonesia". Misi ini tidak terlepas dari pengembangan kompetensi sumber daya manusia di bidang perdagangan. Saat ini tugas pengembangan kompetensi tertumpu pada beberapa lembaga pelatihan yaitu
Pusat Pendidikan dan Pelatihan Perdagangan, Pusat Pengembangan Sumber Daya Kemetrologian, Balai Besar Pendidikan dan Pelatihan Ekspor Indonesia, Balai Diklat Penguji Mutu Barang dan pendidikan tinggi vokasi yaitu Akademi Metrologi.

Pencapaian visi Kementerian Perdagangan seperti yang tertulis di dalam Rencana Strategis 2020-2024 tentu memerlukan upaya konsisten dengan sumber daya manusia yang unggul sebagai penggerak organisasi untuk mencapai visinya di tahun 2024. Dinamika perkembagan zaman dan akselerasi perubahan yang dipicu oleh pandemi Covid19 telah merubah tatanan dunia dengan sangat cepat, sehingga pencapaian visi di tahun 2024 pun seyogyanya memerlukan dukungan alat (tools) strategi yang tepat.

Konsep Corporate University merupakan konsep yang telah lama diadopsi oleh perusahaan-perusahaan korporasi besar di dunia seperti General Electric, Mc Donald dan di Indonesia sendiri konsep ini diadopsi oleh sektor korporasi juga oleh lembaga pemerintah, contohnya Telkom Corporate University dan Kemenkeu Corporate University. Dalam Corporate University ini, pengembangan kompetensi sumber daya manusia tidak lagi bertumpu pada lembagalembaga pelatihan yang tugas dan fungsinya terbatas pada penyelenggaraan pelatihanpelatihan yang seringkali kurang sesuai dengan kebutuhan stakeholdernya. Implikasinya, dengan konsep Corporate University ini pengembangan kompetensi sumber daya manusia di bidang perdagangan dilaksanakan sebagai bagian dari tugas dan merupakan kebutuhan bagi setiap individu yang bergerak di sektor perdagangan.

Corporate University dapat diartikan sebagai sebuah transformasi organisasi yang cukup mendasar. Oleh karena itu, perlu dilakukan kajian lebih mendalam dan kesatuan sudut pandang serta itikad baik untuk mengembangkan kompetensi individu dan organisasi di sektor perdagangan agar Kementerian Perdagangan dapat mencapai visinya di tahun 2024 maupun tujuan organisasi dalam jangka panjang.

Seperti telah disebutkan sebelumnya, Corporate University adalah sebuah entitas 
pembelajaran. Corporate University tidaklah harus berwujud secara fisik dan mempunyai struktur organisasi tersendiri akan tetapi menyatukan mindset elemen-elemen organisasi terutama yang bergerak di bidang pengelolaan dan pengembangan sumber daya manusia. Fungsi utama dari sebuah Corporate University terutama adalah untuk mentransfer dan meng"create" pengetahuan melalui proses belajar yang dinamis. Proses ini tidak hanya didapatkan di dalam kelas-kelas pelatihan saja akan tetapi dapat pula terintegrasi dalam bentuk-bentuk pengembangan kompetensi seperti yang tertulis dalam Peraturan LAN Nomor 10 tahun 2018 tentang pengembangan kompetensi ASN diantaranya yaitu workshop, on the job training, coaching, mentoring dan magang. Model pembelajaran ideal yang lazim diterapkan dalam Corporate University adalah 10-20-70 yang merupakan penerapan pembelajaran terintegrasi untuk lebih
Pengembangan kompetensi individu dan juga organisasi merupakan tanggung jawab dari setiap elemen organisasi itu sendiri. Oleh karena itu, dalam kerangka berpikir Kemendag Corporate University, setiap individu merupakan pembelajar dan juga sumber belajar bagi sekelilingnya.

Corporate University merupakan salah satu pendorong terbentuknya learning organization (Rademakers, 2014). Ilustrasi skema besar yang menjadi penyangga perwujudan konsep Corporate University di Kementerian Perdagangan, disajikan pada Gambar 2. Berikut penjelasan mengenai skema tersebut :

1. Learning Strategy and Governance

Desain konsep kerangka berfikir Kemendag Corporate University sebagai alat strategis organisasi dalam mencapai tujuannya harus diperkuat dengan pondasi berupa strategi dan kepemimpinan pembelajaran yang kuat. Wheeler (2012) menyatakan bahwa
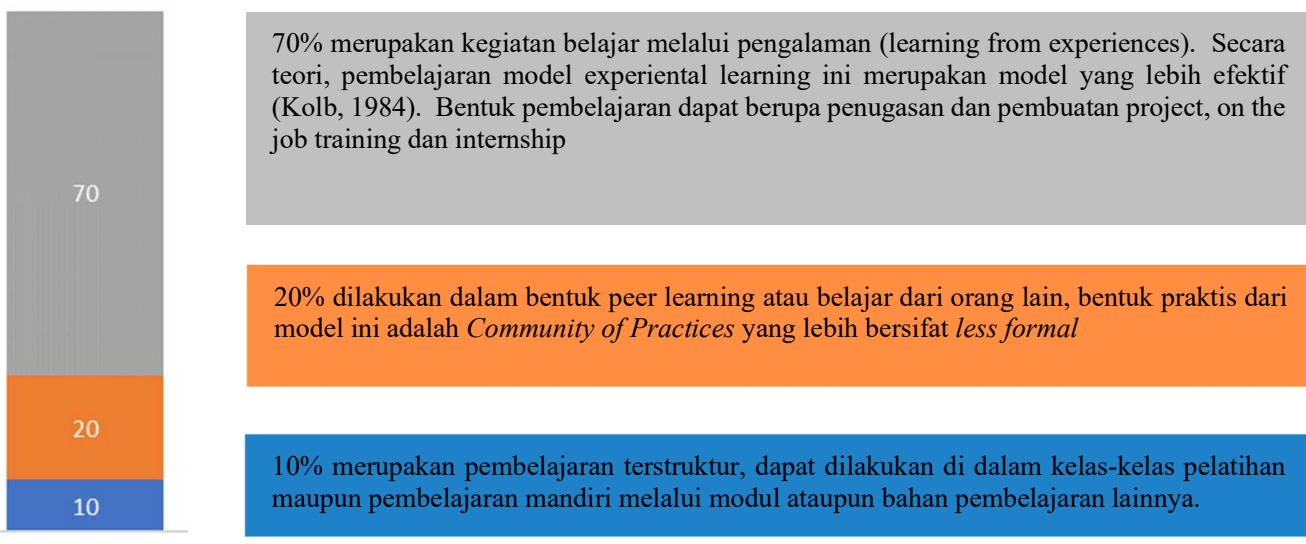

$20 \%$ dilakukan dalam bentuk peer learning atau belajar dari orang lain, bentuk praktis dari model ini adalah Community of Practices yang lebih bersifat less formal
$10 \%$ merupakan pembelajaran terstruktur, dapat dilakukan di dalam kelas-kelas pelatihan

maupun pembelajaran mandiri melalui modul ataupun bahan pembelajaran lainnya.

Gambar 1. Model Pembelajaran 10-20-70

Sumber: Morgan, Lombardo dan Eichinger (1988), dimodifikasi

meningkatkan learning impact terhadap user (unit pengguna). Model ini diperkenalkan oleh Morgan, Lombardo dan Eichinger (1988) dan diterapkan dengan porsi pembelajaran sebagai

Pengembangan Kemendag Corporate University merupakan perubahan yang cukup mendasar bagi organisasi. Dalam sebuah Corporate University, Lembaga Pelatihan yang saat ini ada di bawah Kementerian Perdagangan tidak lagi berdiri sendiri dalam menjalankan tugas dan fungsinya. penerapan konsep ini memerlukan fokus yang jelas, upaya konsisten serta dukungan dari puncak pimpinan adalah mutlak untuk didapatkan. Dengan demikian pengerahan sumber daya untuk pengembangan Corporate University ini dapat lebih efektif dan 
memberikan dampak pada organisasi Kementerian Perdagangan.

2. Integrated Career Path and Human Capital Development

Pilar pertama pengembangan ide sebuah Corporate University di Kementerian Perdagangan adalah terintegrasinya pembelajaran dengan kebutuhan dari dapat menopang kebutuhan pembelajaran organisasi.

3. Knowledge Management

Pembelajaran yang selama ini diselenggarakan oleh lembaga-lembaga pelatihan di Kementerian Perdagangan masih bersifat tersebar dan cenderung tidak terdokumentasikan dengan baik. Ide tentang

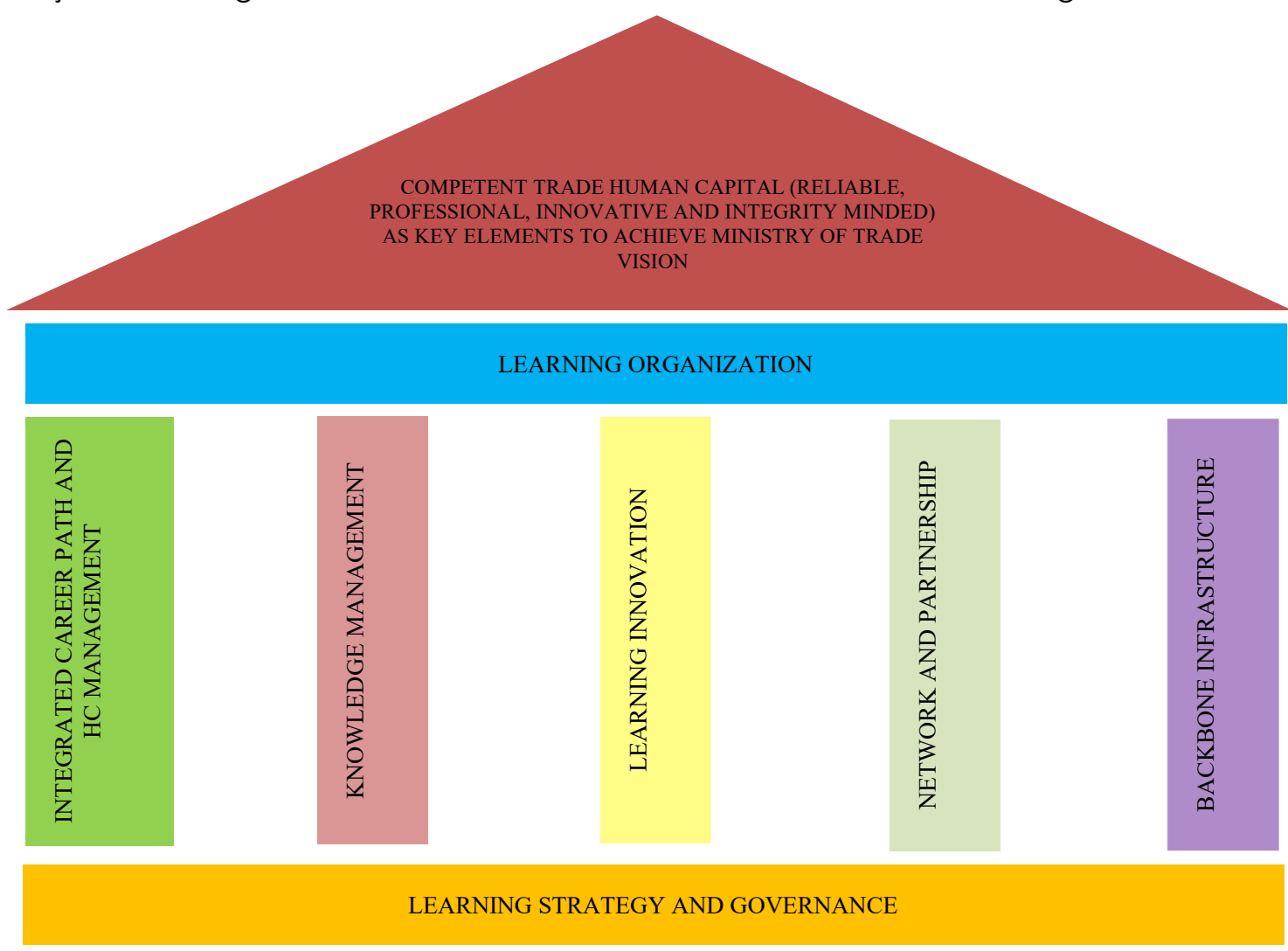

Gambar 2. Konsep Skema Kemendag Corporate University

organisasi itu sendiri. Oleh karena itu, pembelajaran dalam konteks Corporate University tidak terlepas dari pengelolaan dan pengembangan modal insani yang dimiliki/dalam pembinaan organisasi tersebut, sehingga terdapat peta potensi dan kompetensi sumber daya manusia untuk pembelajaran yang dapat diakses oleh pembelajar kapan saja dan dimana saja serta merupakan sumber pembelajaran terkini sesuai dengan kebutuhan organisasi. Dalam hal ini, sistem pengelolaan pengetahuan ini harus bersifat dinamis serta tangkas agar
Pilar Kedua Kemendag Corpu berupa knowledge management ini adalah upaya untuk mengintegrasikan sumber-sumber pembelajaran sehingga dapat diakses oleh pembelajar kapan saja dan dimana saja serta merupakan dokumen/sumber/bahan pembelajaran terkini sesuai dengan kebutuhan organisasi.

4. Learning Innovation

Dalam perspektif Corporate University, pembelajaran tidak hanya berlangsung dalam kelas tatap muka saja. Bahkan seperti dijelaskan sebelumnya, pembelajaran yang terstruktur ini hanyalah merupakan 10 persen dari total pembelajaran yang dilakukan untuk 
mencetak sumber daya manusia yang handal dan kompeten. Oleh karena itu, di dalam Kemendag Corpu, harus dilakukan inovasi terhadap model pembelajaran yang selama ini dilakukan. Pembelajaran terstruktur (10\%) harus dilanjutkan dengan belajar dari orang lain $(20 \%)$ serta penilaian ketuntasan pembelajaran yang dievaluasi di tempat kerja (70\%).

Konsekuensinya, inovasi pembelajaran ini membutuhkan jejaring kerja dan kemitraan yang kuat antara lembaga pelatihan dengan unit kerja teknis dan juga stakeholder lainnya. Inovasi pembelajaran ini juga mencakup penjaminan kualitas pembelajaran, sehingga proses pembelajaran benar-benar dapat menjawab kebutuhan organisasi.

5. Network dan Partnership

Pengembangan Corporate University tidak dapat dilakukan secara parsial oleh masing-masing lembaga pelatihan. Oleh karena itu, diperlukan kolaborasi antara lembaga pelatihan dengan unit kerja teknis maupun mitra pembelajaran lainnya. Sebagai contoh, Telkom Corporate University melibatkan pimpinan dari unit kerja teknis sebagai Faculty member dengan demikian tanggung jawab dalam melakukan pengembangan kompetensi tidak hanya tertumpu pada lembaga-lembaga pelatihan saja.

Selain dari stakeholder internal, akan lebih ideal jika terdapat mitra ataupun faculty member dari stakeholder di luar kementerian sehingga terdapat sumber-sumber belajar yang lebih variatif dan akan memicu proses inovasi pembelajaran selanjutnya.

6. Backbone Infrastructure

Ide tentang pilar kelima Kemendag Corpu adalah Infrastruktur Pembelajaran. Dengan bergesernya paradigma pembelajaran organisasi dari training menjadi learning maka infrastruktur pembelajaran pun berubah sesuai dengan perkembangan zaman dan teknologi yang digunakan.

Porsi pembelajaran terstruktur pada Corporate University hanya tersisa $10 \%$, sehingga seyogyanya ke depan pengadaan untuk infrastruktur tidak lagi difokuskan pada infrastruktur dan fasilitas fisik. 20 dan 70 bagian dari pembelajaran berimplikasi kepada semakin intensnya komunikasi dalam proses pembelajaran. Baik komunikasi dengan rekan kerja ataupun dengan mentor/coach. Peningkatan infrastruktur terkait komunikasi inilah yang penting untuk menjadi fokus prioritas pengembangan Corporate University.

\section{Learning Organization}

Setiap organisasi harus mampu beradaptasi dengan lingkungan yang senantiasa berubah. Terlebih lagi dalam situasi yang sangat dinamis dan penuh ketidakpastian. Tanpa adanya kemampuan untuk belajar, maka organisasi dan individu-individu di dalamnya hanya akan mengulangi praktekpraktek kerja lama yang sudah tidak relevan lagi.

Sebuah studi yang dilakukan oleh Kontoghiorges et.al (2005) mengemukakan beberapa karakteristik organisasi pembelajar yang akan mampu beradaptasi terhadap perubahan yang cepat. Beberapa karakteristik itu diantaranya adalah komunikasi terbuka dan berbagi informasi, keberanian untuk mengambil risiko dan promosi ide-ide baru, tersedianya cukup informasi, fakta, waktu dan sumber daya untuk melakukan pekerjaan dan menghasilkan kinerja yang optimal.

\section{KESIMPULAN}

Inisiasi Kemendag Corporate University seyogyanya dimulai dengan perubahan paradigma tentang pembelajaran (learning) dari seluruh pemangku kepentingan terkait. Pondasi dari pergeseran paradigma ini adalah adanya strategi dan kepemimpinan pembelajaran yang baik dengan inisiatif perubahan yang dimulai oleh puncak pimpinan organisasi.

Terdapat lima pilar Kemendag Corporate University yaitu Integrated Career Path and Human Capital Development, Knowledge Management, Learning Innovation, Network dan Partnership, dan Backbone Infrastructure.

\section{REFERENSI}

Peraturan Menteri Perdagangan Nomor 46 tahun 2020 tentang Rencana Strategis Kementerian Perdagangan.

Peraturan LAN Nomor 10 tahun 2018 tentang pengembangan kompetensi ASN. 
Abel A.L, Li, J. 2012. Exploring Corporate University Phenomenon: Development and Implementation in Comperhensive Survey. Human Resources Development Quarterly Volume 23 (1) 103-126.

Allen, M. 2002. The Corporate University Handbook. AMACOM : New York.

Allen, M. 2007. The Next Generation of Corporate Universities : innovative approaches for developing people and expanding organizational capabilities. Pfeiffer : San Fransisco.

Allen, M. 2014. Talent Management and Corporate Universities: The Intersection of Two Levers Graxiadio Bussiness Review 17 (1), 1-8.

El-Tannir. A.A. 2002. The Corporate University Model For Continous Learning, Training And Development. Education+ Training, 44(2), 76-81.

Gonzales, Didina. 2017. Making of a Corporate University Model : Transition From Traditional Training to Learning Management System. Journal of Education and Practice 8(15), 85-90.

Kontoghiorges, C, Awbre, S, M, Feurig, P, L,. 2005. Examining the relationship between learning organization characteristics and change adaptation, innovation, and organizational performance, Human Resources Development Quarterly Volume 16 Issue 2 p 185-212

Lombardo, Michael M; Eichinger. 1988. The Career Architect Development Planner (1 ${ }^{\text {st }}$ ed.). Minneapolis: Lominger.

Paton, R, Peters, G, Storey, J, Taylor, S. 2005. Handbook of Corporate University Development, Gower Publishing Company, England.

Rademakers, M, 2014, Corporate Universities: Drivers of the learning organization, Routledge, Netherlands

Wheeler, K and Clegg, E, 2012, The Corporate University Workbook: Launching the 21st Century Learning Organization 